\title{
Editorial
}

\section{Después de la ola ómicron: el legado de la pandemia para Brasil}

Las expresiones de agradecimiento al Sistema Único de Salud (sus), el sistema de salud oficial en Brasil que atiende a pacientes críticos y vacuna a la población de forma gratuita, reemplazaron las noticias sobre las deficiencias de atención de la red pública. El signo más, adelante de la palabra sus, agregado en el contexto de las respuestas incorrectas y omisiones del Gobierno federal para enfrentar la pandemia del nuevo coronavirus, es, en principio, contradictorio. El sus se convirtió en héroe, a pesar de que el país perdió más de 620 mil personas, ocupando el primer lugar, en el mundo, en el número acumulado de muertes por habitante.

El reconocimiento de los méritos de una política pública universal y de sus acciones objetivas, y en especial, del trabajo de los profesionales de la salud se dio en varios países. En teoría, los buenos sistemas de salud serían capaces de interponer barreras efectivas para proteger la vida de la población. En los países asiáticos y en Australia y Nueva Zelanda se han llevado a cabo experiencias exitosas en la supresión de casos de Covid-19 [1], lo que evidencia la importancia de las estrategias basadas en la población. El Reino Unido, Italia, Francia e incluso Alemania, a pesar de la adopción de diferentes políticas de contención de la transmisión, tuvieron altas tasas de mortalidad. El país que más gasta en salud en el mundo, Estados Unidos de América, acumula el mayor número de muertes. Bajo este criterio - la prevención de muertes-, los tradicionales sistemas de salud universales europeos y el orientado por el mercado, en América del Norte, habrían sido desaprobados [2].

Sin embargo, los sistemas de salud pública han recibido elogios en general, aun cuando los Gobiernos de los países sean mal evaluados. El amplio apoyo a la salud púbica fue acompañado de la declaración de los profesionales de la salud: "no queremos solo aplausos" en varios idiomas [3], con lo que demandaban la necesidad de condiciones de trabajo adecuadas, que incluían equipos de protección personal, remuneración ajustada a la sobrecarga de trabajo, equipos completos y dotación apropiada de camas, equipos y medicinas.

En Brasil, a pesar de la magnitud de los resultados letales, ha habido un cambio radical hacia un estatus positivo del sus. Bajo el fuego cruzado de los debates sobre el confinamiento y las pruebas versus las políticas menos radicales de cierre de las actividades económicas, la atención a los pacientes, la organización de los servicios y la dedicación de los médicos y las enfermeras, quienes fueron los primeros en fallecer junto a los pacientes de edad avanzada, causaron una enorme conmoción. Se estableció una línea divisoria entre los Gobiernos y las instituciones de salud pública.

La admiración por el sus contó, desde el principio, con la adhesión de líderes de todos los matices políticos. Las controversias giraron en torno a la magnitud de la pandemia, el funcionamiento de las actividades económicas, los medicamentos y las vacunas. Lo que cambió fue la extensión del consenso acerca de las virtudes del sus a los medios de comunicación tradicionales. La experiencia con la COVID-19 convirtió al sus en un talismán nacional. La expresión "si no fuera por el sus sería mucho peor" pasó a ser pronunciada como agradecimiento y respeto. La salud pública se ha convertido en una solución. La valorización del sus, como ocurrió en los países con sistemas públicos universales, fue acompañada por la toma de conciencia sobre la relevancia de la ciencia y la fragilidad de la base tecnológica y productiva del sector. 
La falta de pruebas, oxímetros, cilindros de oxígeno, mandiles, mascarillas quirúrgicas, camas de unidades de cuidados intensivos (UCI) y profesionales de la salud, que evidenciaba la fuerte dependencia de las importaciones de artículos estratégicos y la incompetencia administrativa, pusieron en evidencia antiguos desafíos que se sumaron a la competencia en los procesos de adquisición de insumos favorables a los compradores privados [4]. El sus presentaba más deficiencias que los sistemas de salud de los países ricos. La red capilarizada y potencialmente capaz de realizar acciones de vigilancia epidemiológica en los territorios permaneció desmovilizada y la atención de los casos graves ha sido permeada por actos nobles y de angustia y desesperación de pacientes, familiares y responsables de la atención.

Por lo tanto, el sus se convirtió en un héroe trágico: los intentos de protegerlo lograron resultados insuficientes. Sus inmensas y extensas fallas asistenciales, antes objeto de críticas por problemas de acceso y calidad de las acciones en la red pública, dieron paso a emotivas crónicas de luchas por la vida. Las glorias nacionales, sin embargo, no tuvieron las mismas consecuencias que las otorgadas a otros sistemas nacionales de salud. Las experiencias de pandemia estimularon cambios en las políticas de salud en varios países [5]. Más recursos presupuestarios destinados al área, la valorización de los profesionales de la salud y la intensificación de las conexiones entre instituciones de investigación y desarrollo tecnológico son puntos de una agenda básica y casi consensuada. En Brasil, la marca "Más sus" (Mais sus) ha quedado en el aire y ha sido salpicada por movimientos sociales, medios comerciales y alternativos, pero sin contrapartes objetivas en foros político-partidarios y gubernamentales.

\section{Errores y omisiones}

Desde que se iniciaron los primeros esfuerzos para entender el proceso de transmisión del CoviD-19, los estudiosos brasileños de diferentes áreas del conocimiento alertaron a las autoridades sobre la necesidad de movilizar enérgicamente políticas, programas y acciones para enfrentar la pandemia. Sin embargo, las políticas públicas, impregnadas de errores y omisiones, y sus trágicas consecuencias sanitarias, políticas y económicas, llevaron al país al epicentro de la pandemia, debido a las respuestas tardías e insuficientes para la prevención de casos y muertes. La falta de voluntad, la vacilación y la negativa a contener y controlar la infección rompieron con las buenas tradiciones de vigilancia epidemiológica, las medidas preventivas y la preparación de la atención a los enfermos graves desarrolladas a nivel nacional durante décadas.

Las decisiones tomadas a partir del desconocimiento del control de puertos, aeropuertos y fronteras, el funcionamiento de las actividades económicas y el apoyo financiero a personas y empresas fueron incorrectas y ambiguas. Faltaron insumos estratégicos para la salud y no se llenaron los vacíos en la oferta de recursos asistenciales, y en la actualidad hay escasez de vacunas. Las medidas de protección individual y de la población fueron reemplazadas por ataques a la ciencia y a las experiencias históricas. La legislación promulgada en febrero de 2020 autorizó al Gobierno a movilizar los recursos existentes y amplió el presupuesto público. Sin embargo, las camas privadas y el reajuste de la capacidad instalada para la producción de insumos, como pruebas y mascarillas de mayor calidad y menor costo, y los presupuestos no fueron debidamente dispuestos.

Las estrategias para bloquear la propagación del virus se volvieron inaccesibles, debido a la combinación de cuatro factores: la minimización de la magnitud de la pandemia y el descrédito de las pautas científicas; la adopción de un programa oficial engañoso de "tratamiento temprano" (uso de medicamentos ineficaces) [6]; las políticas insuficientes e intermitentes de asistencia monetaria de emergencia y el retraso en la ampliación de la capacidad instalada de camas de cuidados intensivos; $\mathrm{y}$, por último, las discontinuidades administrativas y la mala gestión financiera en el Ministerio de Salud, así como la inacción de los comités de crisis. La banalización de las muertes y de las secuelas provocadas por la enfermedad, y la difusión de la idea de que solo morirían los ancianos o pacientes con comorbilidades, o aquellos que no tuvieran acceso a un "tratamiento temprano" [7], resumen la negativa a enfrentar la pandemia. De esta manera, en nombre de la "salud de la economía", el Gobierno federal se hizo cómplice de muertes que podrían haberse evitado y no logró revertir la recesión económica. Esta elección política nos llevó a una situación en la que no teníamos políticas efectivas contra el Covid-19, ni mejoras en las tasas de empleo e ingresos.

\section{Muertes evitables, responsabilidades atribuibles}

En situaciones de crisis sanitaria, la responsabilidad de prevenir las muertes en la pandemia recae en los Gobiernos nacionales. En Brasil, el rechazo a las directrices para mitigar los casos y las muertes impidió salvar vidas. Aproximadamente, 120000 muertes, entre las ocurridas hasta finales de marzo de 2021, podrían haberse evitado con medidas de control basadas en acciones de aislamiento social y vigilancia epidemiológica [8]. El exceso de muertes fue mayor en hombres de 20 a 59 años, los negros y los indígenas [9].

Los profesionales de la salud, los trabajadores expuestos a ambientes enrarecidos y aglomeraciones, las personas que viven en asilos y prisiones, los pueblos in- 
dígenas, los quilombolas (comunidades remanentes de la esclavitud) y ribeirinhos (personas que viven en las orillas de los ríos, con difícil acceso a los servicios de salud), y los habitantes de barrios marginales y periferias, y las morbilidades previas debieron ser protegidos de manera prioritaria.

El país lleva más de dos años de pandemia sin implementar las acciones necesarias para enfrentar la propagación del nuevo coronavirus, ahora con el predominio de la cepa ómicron. El desprecio del Gobierno por las vidas ha impedido realizar campañas informativas de salud, movilizar la solidaridad social (convocatoria de los movimientos sociales, las Iglesias, las empresas, los medios de comunicación y las instituciones educativas y de investigación), proporcionar mascarillas de buena calidad, efectuar pruebas de detección y posibilitar la adquisición oportuna de vacunas.

Otro contingente importante de muertes evitables, aunque también difíciles de medir, son aquellas que no pudieron ocurrir por el desempeño efectivo de la red de servicios básicos de salud, es decir, que incluía las pruebas, el seguimiento de casos, las medidas de autoaislamiento y la derivación ágil a hospitales de calidad. El acceso a las pruebas para detectar casos y contactos, que deberían permanecer aislados para reducir el potencial de transmisión, ha sido escaso y desigual en términos de raza/color e ingresos, una inversión inadmisible entre necesidades y obtención de atención, especialmente durante una pandemia. También habría la posibilidad de salvar la vida de los pacientes hospitalizados. Más de 20000 personas fallecieron en 2020 [8], en unidades de atención prehospitalaria o urgencias de la red pública, al no poder acceder a camas de cuidados intensivos. Sería imprudente tener un cálculo preciso de cuántas vidas se hubieran salvado si estas personas hubieran tenido acceso a hospitales y UCI. Pero es importante señalar que la información sugiere la retención del acceso y que las muertes en las instalaciones de urgencia y emergencia no se distribuyeron de manera uniforme. Las muertes se produjeron especialmente en la población que buscó la red pública, compuesta en mayor proporción por negros y personas de menor nivel económico y posiblemente más vulnerables.

\section{Salvar vidas y regenerar el mundo en que vivimos}

El llamado urgente es a salvar vidas mediante una doble estrategia de vacunación y cumplimiento de las medidas de salud pública para protegerse contra la infección. Nadie está a salvo hasta que todos estén a salvo. El presidente de la República, que sigue alentando las aglomeraciones, no se ha vacunado y en un evento multitudinario le quitó la mascarilla a un niño; encarna el estado inconstitucional de la política de salud pública brasileña. Varias iniciativas solicitan: garantizar la asignación del mayor volumen posible de recursos para el sus; imponer pruebas a la población en condiciones de sospecha de infección por COVID-19; distribución gratuita de máscaras Pff-2; recopilación y difusión de datos estadísticos sobre casos confirmados, sospechosos y en investigación; y la creación de un centro nacional de regulación unificada de camas públicas y privadas en UCI.

Por otro lado, el mensaje del Gobierno federal: "tenemos que aprender a vivir con el virus", se cristalizó en consignas vinculadas con el afán de apertura indiscriminada de las actividades económicas. Las vacunas y las medidas de salud pública altamente efectivas hacen posible que no naturalicemos vivir con COVID-19, una infección multiorgánica con consecuencias a largo plazo (COVID largo) para muchos, incluidos los niños. Históricamente, hemos elegido no vivir con infecciones virales graves como la poliomielitis y el sarampión, y contamos con estrategias nacionales y regionales para eliminar estas infecciones.

Limitar la propagación de COVID-19 lo más rápido posible es la mejor defensa contra la aparición continua de variantes más infecciosas. El potencial del país para debatir, formular e implementar estrategias efectivas de salud pública ha sido boicoteado y objetivamente amenazado. No tomar en cuenta la ciencia, atacar a los científicos e incluso ridiculizar las posibilidades de llevar a cabo acciones de atención a la salud socavaron las bases para afrontar las amenazas a la salud pública, fundadas en la certeza de que Brasil ha evitado miles de muertes en experiencias de enfrentamiento de endemias y epidemias anteriores.

La mayoría de los países está transformando sus sistemas de salud, brindándoles recursos humanos, materiales y financieros para proteger a sus poblaciones de los riesgos para la salud. Sin embargo, Brasil todavía está lidiando con sucesivas oleadas de crisis: crisis económica, crisis política, desastres ambientales y aumento de la miseria. Después de ómicron, encontraremos un legado de pérdida, angustia y marginación. Para una parte de la población, el futuro abierto está bloqueado, por la intensificación de las desigualdades y el racismo. Necesitamos desarrollar políticas de salud que contribuyan al sentimiento de pertenencia igualitario y emancipado en el mundo.

Ligia Bahía

Doctorado en Educación

Universidade do Estado do Rio de Janeiro

DoI: https://doi.org/10.17533/udea.rfnsp.e347263 


\section{Fuente de financiación}

Ninguna

\section{Conflicto de interés}

Ninguno

\section{Declaración de responsabilidad}

Se declara que los puntos de vista expresados son responsabilidad del editorialista

\section{Referencias}

1. Skegg DC, Hill PC. Defining covid-19 elimination. BMJ. 2021;374:n1794. DoI: https://doi.org/10.1136/bmj.n1794

2. López Cabello A. Pandemic momentum for health systems financialisation: Under the cloaks of Universal Health Coverage. Global Public Health. 2021;16(8-9):1134-5. DoI: https://doi.org/10.10 $80 / 17441692.2021 .1919736$

3. De Caro W. La necessità di investire nella professione infermieristica:se non ora quando? Professioni Infermieristiche. 2021;74(2):65-66. DoI: 10.7429/pi.2021.742129
4. David Williams O, Yung KC, Grépin KA. The failure of private health services: COVID-19 induced crises in low-and middleincome country (LMIC) health systems. Global Public Health. 2021;16(8-9):1320-33. DoI: https://doi.org/10.1080/17441692.20 21.1874470

5. Sagan A, Webb E, Azzopardi-Muscat, et al. (editors). Health systems resilience during COVID-19. Lessons for building back better. United Kingdom: World Health Organization, European Commision, European Observatory on Health Systems and Policies; 2021.

6. Vinetz JM. Lack of efficacy of hydroxychloroquine in COVID-19. BMJ. 2020; ;369:m2018. DOI: https://doi.org/10.1136/bmj.m2018

7. Centro de Estudos e Pesquisas de Direito Sanitário (CEPEDISA), Faculdade de Saúde Pública da Universidade de São Paulo. A linha do tempo da estratégia federal da disseminação da CoviD-19. Atualizado mediante solicitação da Comissão Parlamentar de Inquérito, por meio do Ofício 57/2021-CPIPANDEMIA. 28 de maio de 2021.

8. Alerta COVID. Mortes evitáveis por COVID-19 no Brasil. Estudo apresentado à Comissão Parlamentar de Inquérito da Pandemia em 23 de junho de 2021.

9. Santos AM dos, Souza BF de, Campos MAG, et al. Excess deaths from all causes and by CoviD-19 in Brazil in 2020. Rev. Saúde Pública. 2021:55:71. Dor: https://doi.org/10.11606/s15188787.2021055004137

Esta obra se distribuye bajo una Licencia Creative Commons Atribución-NoComercial-CompartirIgual 4.0 Internacional

Más información: https://creativecommons.org/licenses/by-nc-sa/4.0/ 